\title{
Observations of expert communicators in immersive virtual worlds: implications for synchronous discussion
}

\author{
Michael Hamilton McVey* \\ Teacher Education, Eastern Michigan University, Ypsilanti, USA
}

(Received 31 March 2008; final version received 8 September 2008)

\begin{abstract}
With the increased interest in using Immersive Virtual Worlds (IVWs) such as Second Life to augment and amplify teaching or to develop communities of practice, the author engaged graduate students, all current K-12 teachers, in a qualitative study to examine their attitudes about communicating for the first time in a virtual setting represented by an interactive avatar. This study sought to determine if students were able to discern degrees of expertise in other avatars by providing encounters with guests who had a significant amount of experience navigating in a virtual world. The study examined Second Life as a synchronous discussion tool for a higher education setting and finds it lacking in some respects, but is able to make recommendations about training instructors to exhibit behaviours that may inspire confidence while leading a class in such a setting.
\end{abstract}

Keywords: synchronous communication; avatars; Second Life

\section{Introduction}

As more instructors in higher education begin using Immersive Virtual Words (IVWs) such as Second Life as a computer-mediated communication platform, researchers will need to revisit earlier work on synchronous communication in consideration of participant utilisation of interactive avatars. Published anecdotal comments inspired by the wide array of avatar shapes and affordances suggest instructors share a range of attitudes about their use. For example, one instructor at the University of Toronto reported a disquieting inability to read the body language of students' avatars in his virtual classroom (Graves 2008), while an instructor from Harvard University perceived outrageous avatars in her classroom as evidence of students enjoying the opportunity to bring their own personality into discussions (Lamont 2007). These two perspectives are representative of the disparate opinions instructors hold as they consider the use of IVWs in their teaching.

For the uninitiated, a participant new to the Second Life environment will choose the body dimensions and clothing for an interactive avatar prior to attending an online class session. Once oriented, it takes knowledge and in-world currency to find and purchase specialised clothing and other adornments or tools. In fact, participants can purchase refinements to the physical shape of their avatar choosing from potentially distracting forms such as gelatinous blobs or hovering stacks of discs. Clothing choices for avatars can include feathers or exotic costumes and tools such as jet packs. It is even possible for a student to arrive in a virtual classroom environment with shimmering fields of light as an adornment.

*Email: mmcvey@emich.edu 
A participant new to the virtual world without resources or general expertise will have an avatar garbed only in the most basic of costumes and relatively free of refinements. Expert users of the IVW will be able to access the profiles of new participants and note an absence of memberships to in-world organisations and sparse inventories of virtual objects. Their lack of adornment indicates, to those experienced with Second Life, a general lack of knowledge and resources. Thus, the construction and maintenance of the avatar has the potential for becoming an identifier of knowledge, status, and even authority. Such visual identifiers extend to observations of the avatars' physical negotiation around objects, teleportation across and between virtual environments, and even the social interactions between avatars.

In a teaching situation or as part of an online community of practice, an instructor may display, through the intermediary of the avatar, an attitude of subject-matter expertise through the proper use of social conventions, choice of avatar costume or enhancements, displays of inventory, knowledge of movement and flight, control of mannerisms and gestures, and a detailed profile with connections to many groups. Even an absence of clumsiness in movement can be indicative of an expertise with the conventions of an immersive virtual world.

It is unclear if instructors possessing such a skill set can use these synchronous communication skills to set the tone in a virtual teaching situation. It is also unclear whether avatar adornments or affordances are necessary to demonstrate the instructor's content area mastery.

\section{Background}

Forms of communication in online learning environments gather into two distinct types: real time or synchronous, and delayed or asynchronous. Research favouring asynchronous communication in an online learning environment suggests that computer-mediated communication through tools such as discussion lists or threaded discussions can benefit students normally shy or reticent to speak aloud in class (Kelley and Keaten 2007). Davidson-Shivers, Tanner, and Muilenburg (2000) compared the qualities of online synchronous and asynchronous discourse to determine whether one discussion environment produced more contentrelated participation than the others. They concluded that synchronous communication provided a direct, immediate environment for responses; however, asynchronous communication, examined through discussion list responses, was delayed but more focused and purposeful. Such a difference might result from students having more time to think about their responses in an asynchronous setting. Increased thinking time improves the depth and quality of responses (Tallent-Runnels et al. 2006). The reliance on synchronous communication in Second Life and other IVWs might suggest some pedagogical inefficiency in formal learning settings.

One of the benefits of engaging students in synchronous communication environments would be what some researchers refer to as the creation of a community of practice (Wenger 1998). Although not a new invention or construction, the concept of a community of practice has taken some interesting turns since practitioners can interact and develop their ability to know and learn through electronic means. Since the mid-1980s, discussion lists and electronic bulletin boards enabled text-based interactions, both synchronous and asynchronous and both with and without moderation. Researchers such as Winograd (2000) explored the effect of a moderator on online conferences, developing a theory that even a low degree of moderation allowed a group to form a community. These communities are defined in terms of camaraderie, support, and warmth. 
Since computer-mediated communication democratises online learning environments (DiMattteo 1990; Rheingold 1993), all learners have the opportunity to participate and contribute. Investigation into how such communities work effectively without external organising or moderation has been hampered by the short-term nature of previous research on online learning communities (Tu and Corry 2002). Primarily, studies have examined end-product messages where the nature of contributions is determined through a close reading of the posts and a derived understanding of their authorship. Even with such limitations, analysis of discourse through end-product messages has demonstrated that effective online communities include contributions ranging from descriptions and humour to articulation and clarification (Chapman, Ramondt, and Smiley 2005).

It is through these social interactions in online communities that participants display subject matter expertise through writing skills that display sensitivity, compassion, and inspiration (McVey 2008). Without a lengthy association with an online community to determine who among members of the community has expertise, participants must find other ways to identify degrees of expertise. In the complex environment of the IVW, expertise can be determined through surface adornments, augmentative devices, and navigation skills of avatars. These reflections of expertise do not necessary convey content expertise but rather communication platform expertise. Newcomers to the virtual world easily recognise these outward displays as signs of a skill set peculiar to the IVW. It is unclear whether instructors who wish to teach within a virtual environment should develop their avatars to display evidence of platform expertise.

Research about the interactions among participants in a text-based online community of practice suggest that instructors establish groups early, model and reinforce effective communication, identify potential problems, and design plans for dealing with these potential problems (Tallent-Runnels et al. 2006). Bielman, Putney, and Strudler (2003) also reviewed the construction of a text-based online community and noted that learners included 'emoticons' such as smiley faces in online communications with one another in an effort to compensate for the missing visual and non-verbal communication cues.

Benefits of engaging in synchronous communications include holding virtual office hours, team decision-making, brainstorming, community building, and dealing with technical issues (Branon and Essex 2001). While synchronous discussions may be more difficult to implement than asynchronous discussions, noted benefits include a greater sense of presence and generating spontaneity (Hines and Pearl 2004).

Synchronous instruction, such as that which occurs in IVWs, requires the simultaneous participation of students and teacher (Romiszowski and Mason 2004). As noted earlier, IVWs are, for the most part, synchronous with a few exceptions being signage and messages on display. The design and architecture found in the IVW itself is a form of asynchronous communication that might serve to encourage and invite one response over another. Directions, visual cues, pathways and colour choices are examples of decisions the architects of interactive environments make which communicate important information, values, and attitudes to the participants. The same communication of values and attitudes can be encountered through the social conventions and mannerisms of avatars as part of the complex interactivity taking place inside the IVW.

In an IVW, participants engage in mannerisms and social conventions to convey their levels of expertise either with the content or the platform, but what it is unclear is the impact these conventions have, if any, on interactions between learners and instructors or facilitators. Observing the social conventions experts display that aid in reducing frustration or assist in enhancing communication might have implications for instructors hoping to hold synchronous sessions in an IVW. 


\section{Methodology}

\section{Research question}

What aspects of avatar construction or social interaction do participants new to IVWs associate with experienced participants?

Subjects in this qualitative study were graduate students taking an online elective course as part of an Educational Media and Technology programme at an American mid-western university. Most were currently working as K-12 classroom teachers and were competent in using technology. Despite a strong interest in technology, most had not experienced an immersive virtual world before but were able to create an avatar and participate in the basic orientation with no intervention on the part of the instructor.

Two groups of five students each participated in an online tour of Second Life in which they were to navigate, with their instructor's avatar, to predetermined locations including replicas of the Sistine Chapel, Tranquillity Base on the Moon, the Globe Theatre, and an aquarium. As part of their experience, students were encouraged to communicate with each other within the virtual environment and actively share their insights with each other about how these three-dimensional replicas might figure into a broader educational setting.

The researcher added an intervention to the tour and did not announce it in advance. In each of these sessions, students engaged with a guest avatar with years of expertise in navigating Second Life and experience interacting with students. One guest expert was a professor in educational leadership and joined students in the lounge area of a virtual church. Another guest expert was a docent at a virtual space flight museum. Both guest avatars approached the group of students and engaged them in conversation about their experiences while their facilitator stood by. The conversations lasted approximately 10 minutes and were concluded by the tour leader on the pretence of needing to continue the tour.

These experienced users simply joined the group as part of the general tour and were not formally introduced as possessing expertise or experience. The guest avatars engaged student participants for approximately 10 minutes then excused themselves as the tour continued. During the tour, participants encountered random avatars in the virtual environment and could join or initiate other conversations in progress if they wished.

After the two-hour tour was completed, students completed an online survey of their experiences. Aside from questions about their previous experience with Second Life, the survey asked two open-response questions. One asked them to discuss anything in the IVW that was a cause of frustration for them. Another question reminded them of their meeting with the guest avatar and asked them to discuss what set the quest apart from other avatars they may have encountered.

The results of the open-ended questions were summarised and categorised into researcher-created typologies based on similarities between the responses. These were counted and recorded. Additionally, the researcher hoped that transcripts of chat sessions from the tours would help to validate responses from the survey. Unfortunately, since some of the participants were using voice-enabled sessions using their own microphones, we were unable to keep records of any private inter-participant conversations.

One element of the course was for students to maintain blogs about their experiences, including those in Second Life. Comments about their interactions with the guests provided additional data.

The responses to the survey, administered immediately after the two-hour tour, were separated into semantic units and grouped by similarity. The researcher then created typologies to categorise the responses based upon terminologies found in the current literature on online communities. The small number of respondents $(n=8)$ provided an opportunity for 
a simple set of typologies which, if the study were to be replicated with a larger sample, could easily be expanded upon.

\section{Results}

Three main groupings of responses were considered in this study: issues of familiarity with the IVW, issues on communication within the IVW, and observations stemming from their interactions with the guest avatars.

\section{Familiarity}

This sample of participants was unique in that none of the eight respondents had ever used Second Life before. Six had not even heard about it prior to their coursework. Consequently, analyses could not be made comparing degrees of experience in virtual environments.

Participants' self-reported degree of familiarity with the virtual environment, choosing one descriptor from a list, described their comfort level in the environment as uncertain (three responses), somewhat confident (three responses), and clumsy (two responses).

\section{Communication}

All but one of the respondents commented about communication issues and voiced similar concerns that their inexperience with navigation and reading the stream of Instant Messages caused them to lose contact with the larger group. Specific concerns about loss of communication with the group were the result of technical issues (three responses), navigation issues (three responses), inexperience with Instant Messaging (two responses), and their inability to search for classmates (one response).

\section{Guest avatars}

Using the researcher-created set of typologies, comments about the guest avatars from both the surveys and student blogs were assigned into categories for ease of analysis. These categories were: (1) Mannerisms; (2) Interaction; (3) Appearance; and (4) Messaging.

\section{Mannerisms}

Participants were keenly aware of avatars with a significant knowledge of Second Life. They took note of the following mannerisms: (1) asking permission to join conversations in progress; (2) ease of movement, especially the ability to fly; and (3) smooth navigation around virtual objects such as chairs.

\section{Interaction}

Participants made several comments in both the surveys and their blogs based on engaging these guest avatars. Primarily, these comments could be summarised as: (1) conversations with the guest avatars calmed their agitation about the virtual world; (2) guest avatars' fluid movements were equated with experience and expertise; and (3) guest avatars encouraged participation in the discussion. Of greater concern to them was their own inability to make their avatar move naturally. The guest avatars made navigation appear very natural. 


\section{Appearance}

Participants made almost no reference to the customised appearances of expert avatars who boasted only simple adornments such as a pony tail and a clipboard. One commented in a blog entry about the large bat wings on a randomly encountered avatar. Avatar appearance did not appear to be a significant factor in determining the expertise level of the guest avatars. In only one case did the avatar's clothing appear to lend comfort to a new participant and that was in reference to the instructor's avatar which wore a tuxedo jacket and tie, chosen specifically to lend an air of authority.

\section{Messaging}

Participants also noticed the behaviour of the guest avatars when engaged in Instant Messaging. In Second Life, one may communicate directly with a microphone but many of the new participants used text in the form of Instant Messages. Several participants noted that the guest avatars: (1) posted only short lines of text; (2) did not usually post complex thoughts in a single message; and (3) broke long messages into several short ones. This last activity made it easier for new participants to read quickly and participate in the synchronous discussion. Overall, this consideration of the limitations of the medium is a characteristic that set guest avatars apart from the new participants and random encounters with other avatars.

\section{Discussion}

Despite the fact that none of the eight respondents had ever visited Second Life before, they were enthusiastic about their experience and eager to navigate the virtual world. Their primary goal for taking the tour was to consider educational applications for IVWs in a broader learning environment such as a secondary school setting. One idea that emerged from this conversation was the idea of performing plays on a model of the Globe Theatre. The instructor designed the objectives for this exploration to be as flexible as possible because of the variety of teaching backgrounds of the participants. What was interesting and noteworthy in reviewing their comments on the survey and in their blogs was the degree of similarity in their responses.

Although technical issues varied among respondents, almost to a person they noted a concern about losing contact with the whole group. This loss of contact came about through navigation difficulties, inexperience with some of the communication tools, and an inability to use search tools to find their colleagues. Students can overcome these issues with time, experience, and training in the environment, but for the first time exploring these environments, separation from the group was a discomforting experience. They relied on their classmates to help them to figure out the experience.

From the perspective of an instructor attempting to organise a classroom in the Second Life environment, it appears to be a highly valuable practice to keep the group together at first. Taking close note that all of the members of the group have transported with you from one area to another will prevent disorientation, confusion, and frustration.

Instructors new to Second Life should be keenly aware of the way they communicate with their students. This study offers several suggestions based upon the observations gathered and recorded by new participants when they encounter other avatars with far more experience in the virtual world. The lessons learned deal with communication, social conventions, and navigation. 


\section{Communication should be in short bursts}

It appears that short bursts of information are best in this environment. It also appears that instructors should set aside sufficient time for their students to explore movement and communication in the virtual environment. Students should be encouraged to practice moving their avatars, include gestures in their communications, and avoid excessive Instant Messaging unless answering a question. The instructor should consider the entire experience as an exercise in communication and should be keenly aware of the potential for frustration on the part of the participants.

\section{Avatar movements should follow social conventions}

Even students new to Second Life appear to be sensitive to social aspects of communication. After a demonstration of how to make an avatar produce gestures such as a wave, students were anxious to learn how to make their own avatars gesture. The ability to gesture soon became part of the communication skill set the participants used. Social conventions, such as approaching then standing just beyond an ongoing conversation then asking permission to interact with strangers, appear to be skills mastered by the experienced guests. Understanding these unspoken rules may assist students in having positive experiences in a virtual learning environment, especially when they explore on their own.

\section{Time to explore is time well spent}

For students new to the Second Life environment it would be wise to allow practice time to overcome navigation issues, to ensure the varied computer systems can manage the software, to make certain microphones work if they are being used, and to train students to write shorter statements when using Instant Messaging.

\section{Conclusions}

Immersive Virtual Words certainly generate a great deal of excitement and enthusiasm on the part of students and instructors alike, especially those in higher education settings. Instructors considering the use of such a tool should realise there is just as much potential for enhanced communication with their students as there is for impeded communication.

The observations of graduate students new to IVWs as they interact with experts familiar with conventions and navigation within virtual worlds are instructive for professors considering using such affordances for the first time. In addition to the number of steps a student must take to acquire the software, create an avatar, and learn how to navigate, there is a great deal of reported anxiety about the experience. Instructors would be wise to take such factors into account in order to create an experience focused more on the content than the platform.

For the instructor new to the IVW, a lack of awareness of mannerisms and social conventions in the virtual environment can easily become debilitating and make even the most competent instructor in a face-to-face classroom appear clumsy and awkward in front of virtual students. Taking time to acquire some digital adornments or a more extensive electronic wardrobe would be one way to prepare for hosting a class in an immersive environment. Of even greater value would be the mastery of basic navigation and learning a few social conventions from a colleague familiar with IVWs.

Of course, it is always the content and quality of the message that is of the utmost value but, from the perspective of an instructor, the message must always be properly framed. In 
the virtual environment, this proper framing requires work from the instructor. It includes knowledge of navigation and movement, a collection of appropriate adornments or costumes, and an awareness of mannerisms and social conventions.

\section{References}

Bielman, V., L. Putney, and N. Strudler. 2003. Constructing community in a postsecondary virtual classroom. Journal of Educational Computing Research 29, no. 1: 119-44.

Branon, R.F., and C. Essex. 2001. Synchronous and asynchronous communication tools in distance education: A survey of instructors. TechTrends 45: 36-42.

Chapman, C., L. Ramondt, and G. Smiley. 2005. Strong community, deep learning: Exploring the link. Innovations in Education and Teaching International 42, no. 3: 217-30.

Davidson-Shivers, G., E. Tanner, and L. Muilenburg. 2000. Online discussion: How do students participate? Paper presented at the American Educational Research Association, 26 April, in New Orleans, LA.

DiMattteo, A. 1990. Under erasure: A theory for interactive writing in real time. Computers and Composition 7: 71-84.

Graves, L. 2008. A Second Life for higher ed: A virtual world offers new opportunities for teaching. US News and World Report 2008. http://www.usnews.com/articles/education/e-learning/2008/ 01/10/a-second-life-for-higher-ed.html.

Hines, R.A., and C.E. Pearl. 2004. Increasing interaction in web-based instruction: Using synchronous chats and asynchronous discussions. Rural Special Education Quarterly 23: 33-6.

Kelley, L., and J.A. Keaten. 2007. Development of the affect for communication channels scale. Journal of Communication 57, no. 2: 349-65.

Lamont, I. 2007. Teaching in Second Life: One instructor's perspective. http://terranova.blogs.com/ terra_nova/2007/05/teaching_in_sec.html.

McVey, M. 2008. Shared leadership in informal online learning communities. Paper presented at the Society for Information Technology in Education, 3 March, in Las Vegas, NV.

Rheingold, H. 1993. The virtual community. New York: Addison-Wesley.

Romiszowski, A., and R. Mason. 2004. Computer-mediated communication. In Handbook of research on educational communications and technology, ed. D.H. Jonassen, 397-432. Mahwah, NJ: Lawrence Erlbaum.

Tallent-Runnels, M.K., J.A. Thomas, W.Y. Lan, S. Cooper, T.C. Ahern, S.M. Shaw, and X. Liu. 2006. Teaching courses online: A review of the research. Review of Educational Research 76, no. 1: 93-135.

Tu, C.-H., and M. Corry. 2002. Research in Online Learning Community. http://www.usq.edu.au/ electpub/e-jist/docs/html2002/chtu.html.

Wenger, E. 1998. Communities of practice: Learning, meaning, and identity. Cambridge: Cambridge University Press.

Winograd, D. 2000. The effects of trained moderation in online asynchronous distance learning. Paper presented at the Association for Educational Communication and Technology, 25 October, in Denver, CO. 